\title{
Ulrich Köpf, Martin Luther. Der Reformator und sein Werk
}

\section{Gérald Chaix}

\section{OpenEdition}

Journals

Édition électronique

URL : http://journals.openedition.org/ifha/9158

DOl : $10.4000 /$ ifha. 9158

ISSN : 2198-8943

\section{Éditeur}

IFRA - Institut franco-allemand (sciences historiques et sociales)

\section{Référence électronique}

Gérald Chaix, "Ulrich Köpf, Martin Luther. Der Reformator und sein Werk », Revue de l'IFHA [En ligne], Date de recension, mis en ligne le 14 juin 2018, consulté le 24 septembre 2020. URL : http:// journals.openedition.org/ifha/9158; DOI : https://doi.org/10.4000/ifha.9158

Ce document a été généré automatiquement le 24 septembre 2020

(CIFHA 


\title{
Ulrich Köpf, Martin Luther. Der Reformator und sein Werk
}

\author{
Gérald Chaix
}

\section{RÉFÉRENCE}

Ulrich Köpf, Martin Luther. Der Reformator und sein Werk, Stuttgart: Philipp Reclam, 2015, 254 p., $22,95 €$ 
C'est dans la célèbre collection « Reclam » qu'est parue la biographie rédigée par Ulrich Köpf, professeur d'histoire ecclésiastique à l'université de Tübingen et responsable scientifique de l'édition des œuvres de Luther, dite de Weimar, jusqu'à l'achèvement de l'entreprise en 2009. C'est d'ailleurs à la présentation des sources de notre connaissance de Luther et des questions toujours pendantesqu'U. Köpf consacre le premier des trentehuit chapitres qui composent cette présentation, succincte mais claire et bien informée, de la vie et de l'œuvre du réformateur. Pour l'auteur, qui conclut ainsi, Luther est un "homme de Dieu " mais aussi, pour ses adversaires, un « hérétique ». Il appartient au Moyen Âge mais est également un novateur: il contribue au renouvellement de la théologie et marque de son empreinte la

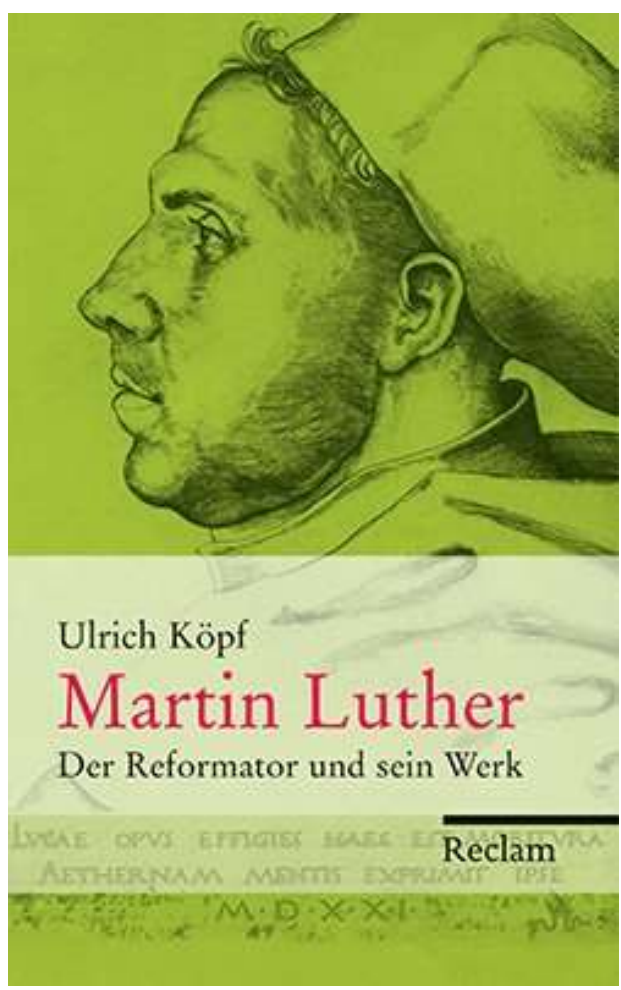
langue allemande. Avec lui, le pluralisme religieux s'impose. Ces fils conducteurs sont suivis selon un plan strictement chronologique: la jeunesse (jusqu'en 1505), l'entrée au couvent, l'expérience conventuelle, la formation universitaire et le professorat de théologie à l'université de Wittenberg, où il succède à Johannes Staupitz, son " père spirituel ». Il y fait cours sur les Psaumes et utilise à cette occasion aussi bien les outils de travail élaborés par les humanistes que les commentaires, préscolastiques, de Bernard de Clairvaux. Il approfondit sa réflexion sur la "justice de Dieu», aidé en cela par ses lectures de saint Augustin. Sa démarche, progressivement partagée par ses trois autres collègues de la faculté de théologie, le détourne de la théologie scolastique.

C'est dans cette dynamique collective que s'inscrit la publication des thèses sur les indulgences en octobre 1517. Elles sont réimprimées dès 1517 à Leipzig, à Nuremberg et à Bâle, bien au-delà du monde universitaire auquel elles étaient d'abord destinées, tandis que Luther les complète, en 1518, par deux écrits explicatifs. Le procès en hérésie est instruit. L'autorité pontificale, défendue aussi bien par le dominicain Prierias que par le cardinal Cajetan, rencontré lors de la Diète qui se tient à Augsbourg en octobre 1528, devient l'enjeu principal. Lors de la « dispute » organisée à Leipzig (fin juin-mi-juillet 1519), Johannes Eck rapproche Luther de Jan Hus, brûlé pour hérésie en 1415. Ces oppositions ne font pas taire Luther. Elles le poussent à préciser sa pensée tout au long de l'année 1520. Ses écrits, largement diffusés, sont accueillis avec enthousiasme et très souvent réédités. Luther est finalement excommunié et mis au ban de l'Empire lors de la Diète de Worms, où il est confronté à Charles Quint les 17 et 18 avril 1521. Durant dix mois, il est caché au château de la Wartburg. Il y déploie une intense activité, mettant en chantier notamment la traduction de la Bible en allemand (achevée en 1534) qu'il débute par celle du Nouveau Testament (publiée en septembre puis en décembre 1522). Pendant ce temps, à Wittenberg, des clercs remettent en question leur célibat ou, chez les Augustins, leur mode de vie conventuel, tandis que 
des changements sont introduits dans les cérémonies liturgiques. Revenu à Wittenberg en mars 1522, Luther se réinstalle dans son couvent quasiment déserté, récupère son froc, retrouve son activité universitaire et s'efforce de reprendre en main les évolutions. Il précise alors l'attitude à adopter face à l'autorité civile et esquisse la conception des deux royaumes. Il défend son appel à l'obéissance face aux «réformateurs radicaux »-Karlstadt, Müntzer - dont il condamne par ailleurs les positions théologiques concernant les images et le sacrement de l'eucharistie.

Sa condamnation des soulèvements paysans s'inscrit dans cette veine. Elle écorne cependant son image. Son mariage, en juin 1525, souligne sa rupture avec la vie monacale. Il rompt également avec Érasme, auteur d'une défense du libre arbitre. Il dénonce la doctrine et les prédications des "anabaptistes». Il soutient le développement des réformes en Saxe électorale et, face à l'avancée des Turcs jusqu'aux portes de Vienne, justifie la lutte armée contre eux. Le financement de la guerre est d'ailleurs l'une des raisons de la prudence adoptée par l'empereur face à Luther afin de se concilier villes d'Empire et princes territoriaux. Du même coup, les réformes s'étendent dans les villes, notamment les villes libres d'Empire, et un certain nombre de territoires. Elles ne sont pas exemptes de différences, notamment sur la question de la Cène, avec les positions de Luther. En 1530, à l'occasion de la Diète d'Augsbourg, à laquelle assiste Charles Quint, une profession de foi, ainsi dite d'Augsbourg, est rédigée. La territorialisation du mouvement réformateur est confirmée par la mise en place de la ligue de Smalkalde qui fait suite. En dépit d'une santé chancelante, Luther poursuit son activité. Il rejette l'idée du concile, que le pape Paul III (1534-1549), avec l'appui de Charles Quint, veut réunir. Il fait de l'université l'une des forces vives du processus réformateur (enseignement, disputes, formation et ordination des pasteurs, défense de l'orthodoxie doctrinale). Il s'efforce de promouvoir l'unité du camp réformateur, quitte à fermer les yeux sur le double mariage du landgrave Philippe de Hesse. Il dénonce avec une force, voire une agressivité, toujours plus grande ses adversaires : les «Schwärmer ", les théologiens de Louvain, les Turcs, les Juifs (s'éloignant de l'attitude plus favorable qu'il avait adoptée à leur égard en 1523) et surtout la papauté, instrument du diable. Victime d'un infarctus, il meurt à Eisleben dans la nuit du 17 au 18 février 1546. Présent, Justus Jonas, fidèle compagnon du réformateur, veille efficacement à la mise en scène d'une «bonne mort ». La dépouille de Luther est ramenée à Wittenberg le 22 février. L'oraison funèbre y est faite en allemand par Bugenhagen, et en latin par Melanchthon. Le temps est venu de mettre en œuvre son enseignement et de rester fidèle à sa mémoire.

\section{INDEX}

Index chronologique : Période moderne

Thèmes : Histoire religieuse ; Histoire des mentalités 


\section{AUTEURS}

GÉRALD CHAIX

Université de Tours, UMR 7323 